\title{
Erratum to: The Membrane Electrowinning Separation of Antimony from a Stibnite Concentrate
}

\author{
JIAN-GUANG YANG, SHENG-HAI YANG, and CHAO-BO TANG
}

DOI: $10.1007 / \mathrm{s} 11663-012-9791-7$

(C) The Minerals, Metals \& Materials Society and ASM International 2013

\section{Erratum to: METALLURGICAL AND \\ MATERIALS TRANSACTIONS B, VOL. 41B, PP. 527-34 DOI: 10.1007/S11663-010-9353-9}

THE following images are corrections of the original figures due to new validated experimental results in which the authors found that the original figures did not show the representative results.

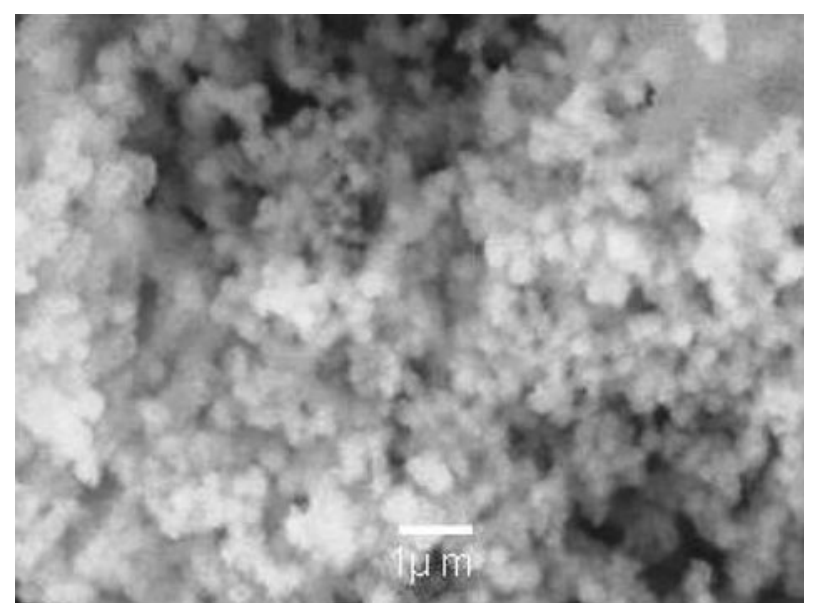

Fig. 3-An SEM image of the antimony electrodeposit (the Sb concentration in catholyte is $25 \mathrm{~g} / \mathrm{L}$ ).

JIAN-GUANG YANG, Associate Professor, is with the Department of Metallurgical Science and Engineering and the Institute of Powder Metallurgy Research, Central South University, Changsha 410083 P.R. China. Contact e-mail: jianguang_yang@hotmail.com SHENG-HAI YANG and CHAO-BO TANG, Associate Professors, are with the Department of Metallurgical Science and Engineering, Central South University, Changsha 410083, P.R. China.

The online version of the original article can be found under doi: 10.1007/s11663-010-9353-9.

Article published online February 12, 2013.

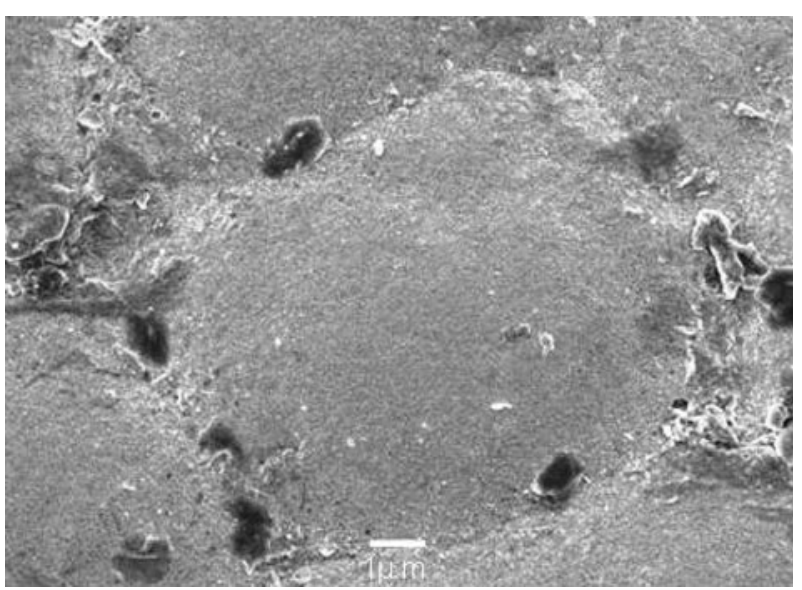

Fig. 4-An SEM image of the antimony electrodeposit (the Sb concentration in catholyte is $75 \mathrm{~g} / \mathrm{L}$ ).

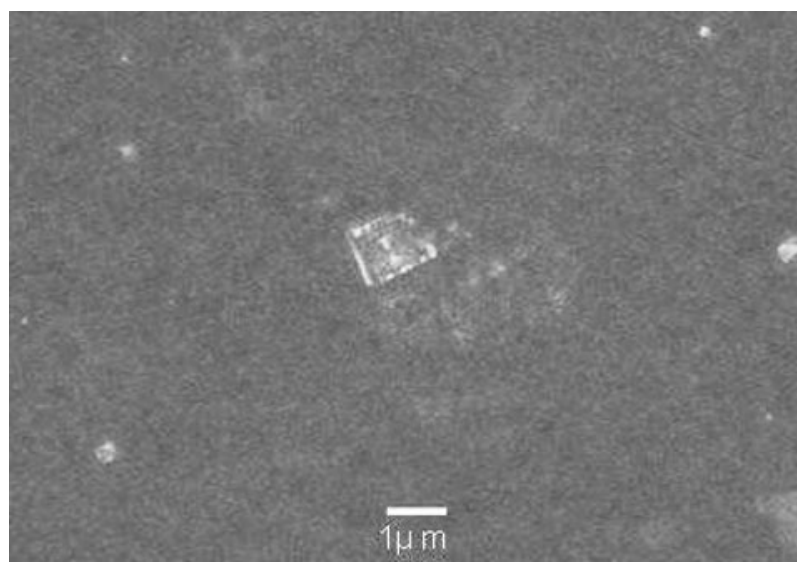

Fig. 5-An SEM image of the antimony electrodeposit (the $\mathrm{NaCl}$ concentration in catholyte is $5 \mathrm{~g} / \mathrm{L}$ ). 


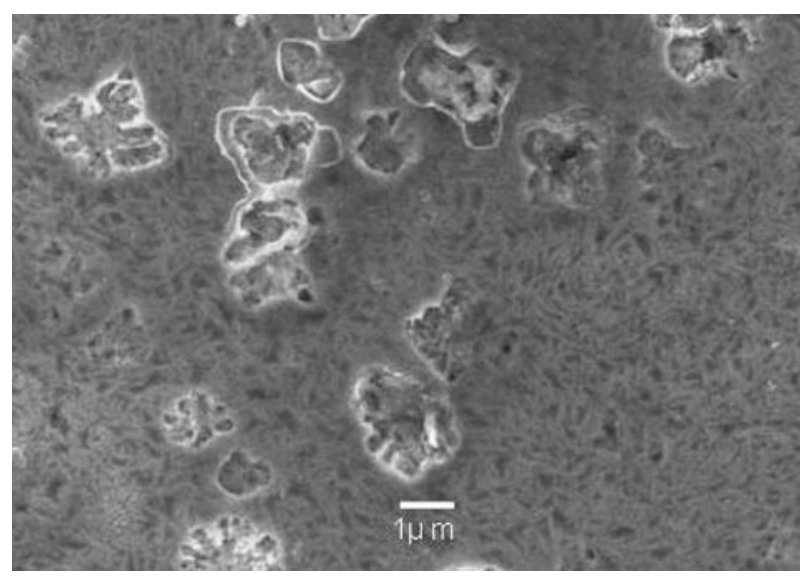

Fig. 6-An SEM image of the antimony electrodeposit (the $\mathrm{NaCl}$ concentration in catholyte is $30 \mathrm{~g} / \mathrm{L}$ ).

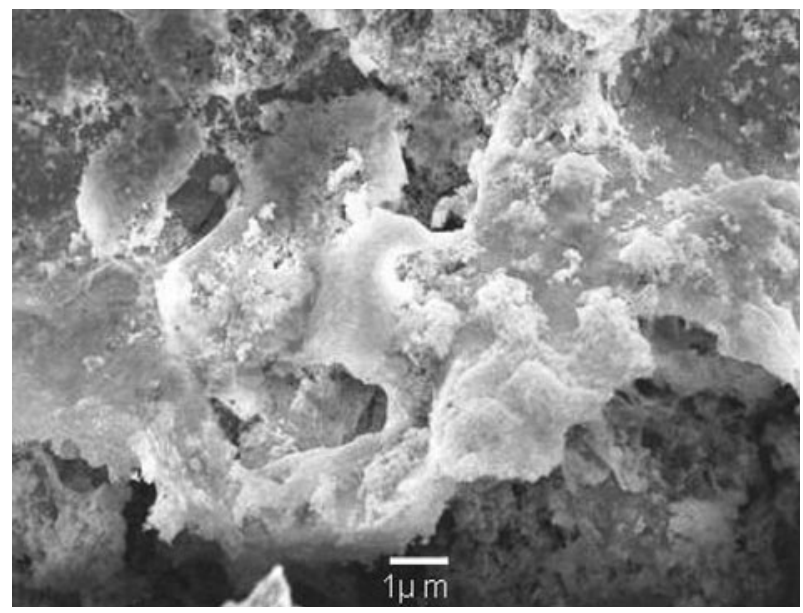

Fig. 7-An SEM image of the antimony electrodeposit (the electrowinning temperature is $\left.298 \mathrm{~K}\left(25^{\circ} \mathrm{C}\right)\right)$.

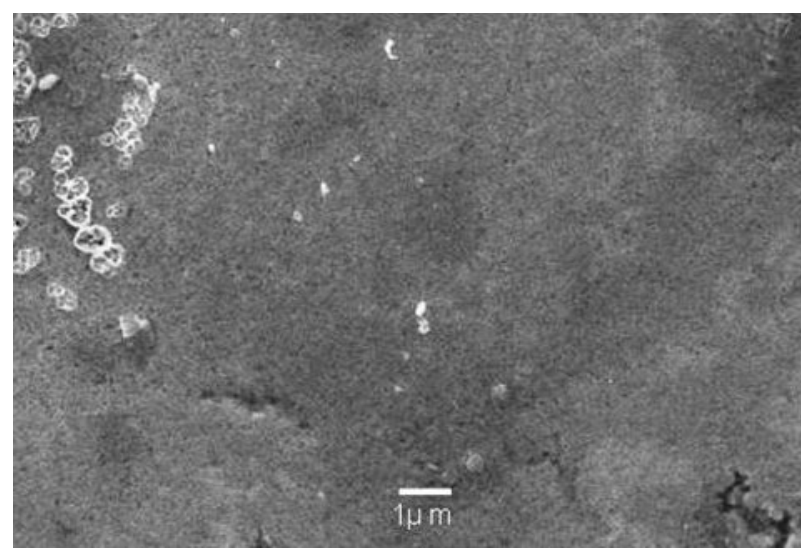

Fig. 8-An SEM image of the antimony electrodeposit (the electrowinning temperature is $\left.338 \mathrm{~K}\left(65^{\circ} \mathrm{C}\right)\right)$.

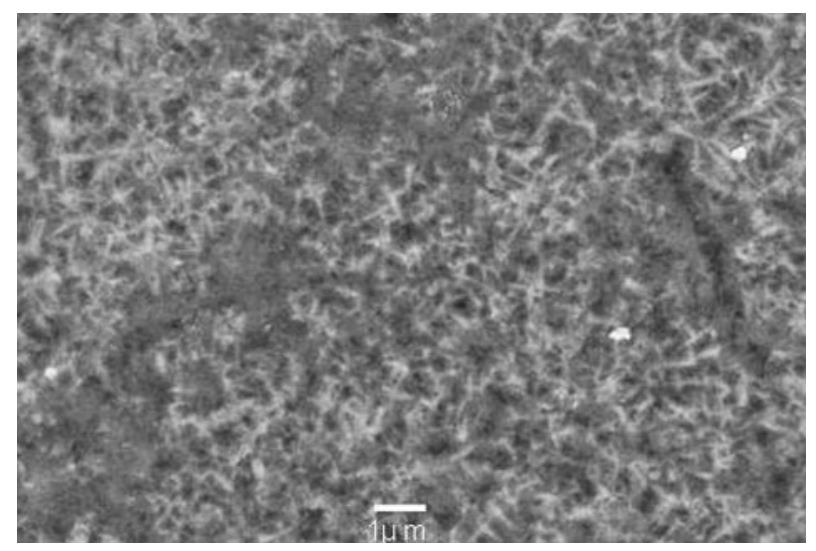

Fig. 9-An SEM image of the antimony electrodeposit (the cathode current density is $100 \mathrm{~A} / \mathrm{m}^{2}$ ).

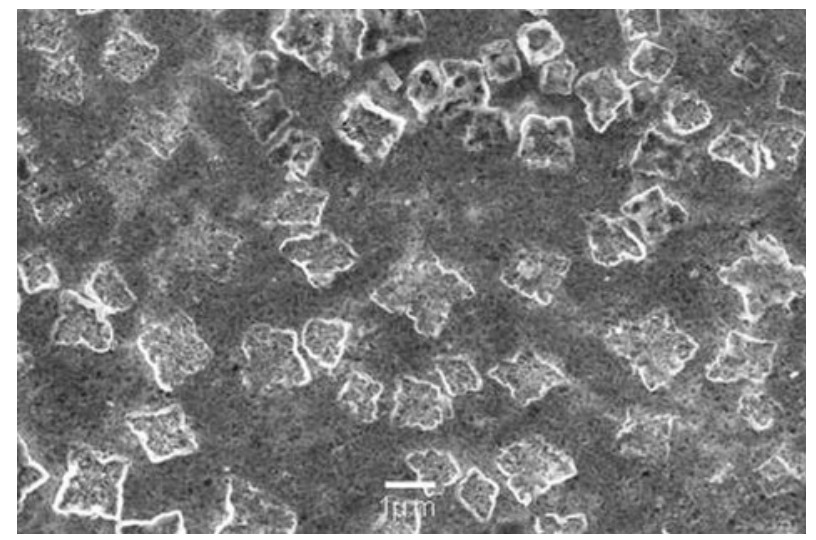

Fig. 10-An SEM image of the antimony electrodeposit (the cathode current density is $300 \mathrm{~A} / \mathrm{m}^{2}$ ).

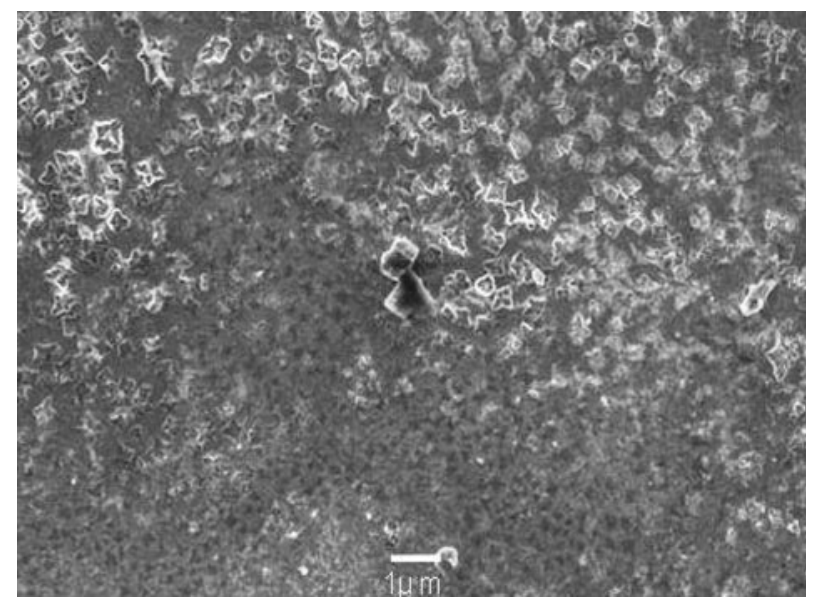

Fig. 11-An SEM image of the antimony electrodeposit (the polar distance is $3 \mathrm{~cm}$ ). 


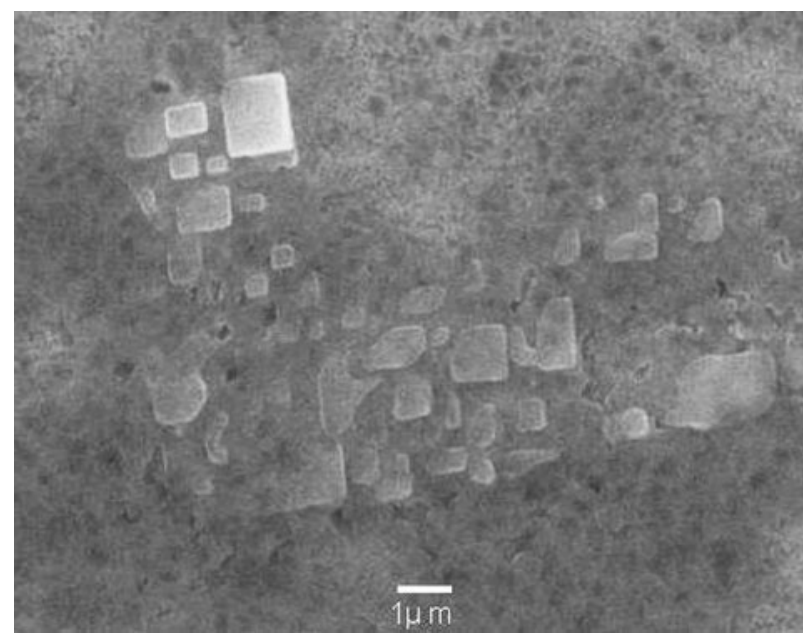

Fig. 12-An SEM image of the antimony electrodeposit (the polar distance is $6.5 \mathrm{~cm}$ ).

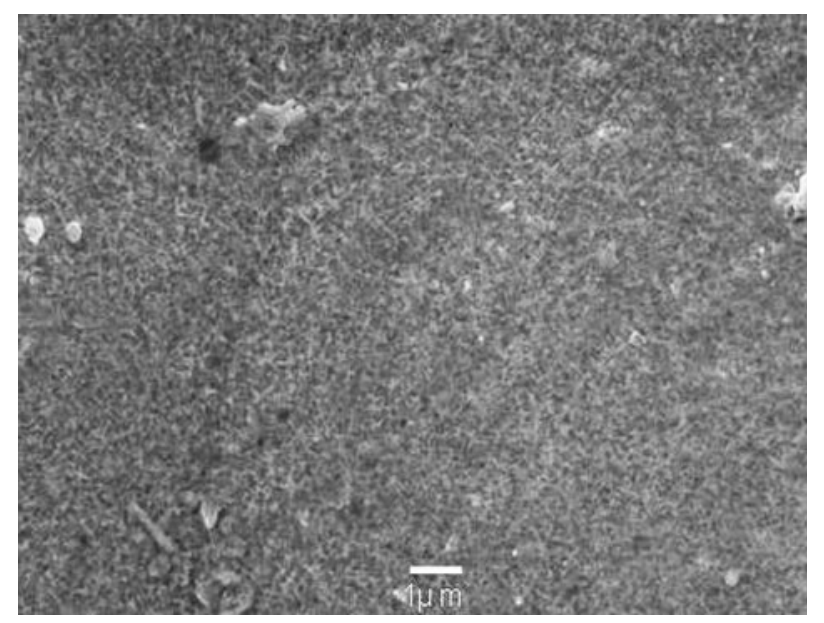

Fig. 13-(2) - An SEM image of the Sb electrodeposit of the confirmation experiment. 